\title{
A dor, a glória e o charme butch de Esther Newton
}

\author{
The Pain, the Glory and the Butch Charm of Esther Newton
}

Carlos Eduardo Henning' (iD 0000-0003-2103-2821

'Universidade Federal de Goiás, Faculdade de Ciências Sociais, Goiânia, GO, Brasil. 74020-020-ppgasufg@yahoo.com.br

\section{$-$}

NEWTON, Esther.

My Butch Career: A memoir.

Durham: Duke University Press, 2018, 274p.

A antropóloga feminista Gayle Rubin (2016, p. 117) afirma que há uma dificuldade imensa em garantir o compartilhamento do que chama de "camadas geológicas de conhecimentos queer" sobre diversas "comunidades sexuais minoritárias", de maneira a que novas gerações de investigadoras/es não suponham estar reinventando a roda. Nessa perspectiva, a vida, a carreira e a obra pioneira da também antropóloga Esther Newton fariam parte de uma das mais relevantes camadas desses 'estratos geológicos'.

Tive a oportunidade de conhecer e conversar com Newton - e de posteriormente entrevistála - no início de 2019 ao longo de duas conferências de lançamento de seu livro mais recente My Butch Career: a memoir (2018) - na cidade de Nova lorque. ${ }^{1}$ Tendo lido o referido livro posso afirmar que ele é pródigo por seus múltiplos usos, qualidades e potências. Tal obra contribui para a compreensão das condições, dos desafios e das consequências de se viver na dissidência sexual e de gênero e ainda ousar contribuir para a produção dessas camadas de "conhecimentos queer" ao longo da segunda metade do século passado. Através de onze capítulos acompanhamos a narrativa sedutora da antropóloga - a qual integra a primeira geração de intelectuais do "movimento gay liberacionista" nos Estados Unidos - sobre a sua própria "carreira butch". ${ }^{2}$

Nascida na cidade de Nova lorque em 1940, Esther Newton se tornou uma importante referência ao publicar o livro Mother Camp: Female Impersonators in America em 1972. Esta etnografia, hoje clássica, foi resultado de sua tese de doutorado orientada por David Schneider no Departamento de Antropologia da Universidade de Chicago e analisa o universo das female impersonators, ou drag queens, em duas cidades estadunidenses na primeira metade dos anos

\footnotetext{
' Tal encontro ocorreu no contexto do pós-doutorado que venho realizando como visiting-scholar no Institute of Latin American Studies da Columbia University na cidade de Nova lorque.

2 "Butch" é uma categoria associada às mulheres lésbicas mais masculinas, as quais, nos bares lésbicos no Greenwich Village dos anos 1950 e 1960, em Manhattan, Nova lorque, costumavam se interessar e se relacionar com as "femmes". "Butch" poderia ser traduzida ao português brasileiro - com riscos de anacronismo e consideradas as distinções semânticas - como "sapatão" e em castelhano como "camionera", "marimacho" ou "chonga" (essas categorias, no entanto, variam amplamente dependendo do país em questão). Agradeço à antropóloga Andrea Lacombe pelas sugestões de categorias correspondentes no caso argentino.
} 
1960. ${ }^{3}$ Em uma época em que estudos antropológicos em contextos urbanos ocidentais eram incomuns, tal publicação contribuiu para o desenvolvimento da antropologia urbana, além de alçar Newton a precursora do campo de estudos antropológicos sobre gênero e sexualidade, assim como do campo mais amplo de estudos LGBT's. Mais recentemente, inclusive, a obra tem sido reposicionada também como uma antepassada dos estudos queer (Gayle RUBIN, 2018a; 2018b).

No entanto, em vários pontos de My Butch Career Newton aborda, com certa amargura, 0 fato de Mother Camp ter sido praticamente ignorado na época de seu lançamento. Ela também afirma que até o início dos anos 1980 suas pesquisas e publicações não possuíam quase nenhuma audiência ou reverberação. Por outro lado, a autora reconhece que seu livro primogênito se mostrou muito influente a posteriori, tornando-se referência central para obras canônicas como as de Rubin $(1975$; 1984) e mesmo, duas décadas depois, para a teoria da performatividade de gênero da filósofa pós-estruturalista Judith Butler (2003).

De antemão, um dos triunfos do recente livro de memórias de Newton talvez resida justamente em contextualizar de modo vívido e instigante - através do percurso biográfico da autora - um conjunto de profundas transformações sociais em diversos âmbitos como: a) na antropologia cultural norte-americana a partir dos anos 1960; b) no universo acadêmico fortemente machista, homofóbico e racista das universidades da época; c) nos movimentos feministas da segunda onda em diante; d) nos movimentos homófilos e de liberação homossexual; c) na maneira como identidades sexuais e de gênero se reconfiguraram no período em questão; d) e nas próprias condições para a recepção e o reconhecimento das obras de Newton e de intelectuais de sua geração. Para além disso, diga-se de passagem, a obra também é atravessada por passagens altamente envolventes sobre as diversas conquistas amorosas e love-affairs da autora, o que enriquece e complexifica o livro de diversas maneiras.

Já no início, My Butch Career mostra o seu vigor em fazer pensar sobre transformações identitárias, diferenças geracionais e mesmo sobre o curso da vida. Uma interessante passagem se dá quando Newton discorre sobre se compreender como "lésbica butch" ao invés, por exemplo, de se identificar como "homem trans". Para tanto, ela aborda uma questão que muitas vezes the foi direcionada:

Por que não fazer a transição [de gênero]? Fatores geracionais e autobiográficos são as razões mais importantes. Quando criança eu não pensava em mim como um garoto preso no corpo de uma garota. [...] [No entanto] Recentemente eu assisti a um excelente documentário da PBS Frontline chamado Growing Up Trans. [Crescendo como Trans] [...] Tive que encarar o fato de que estava vendo a eu mesma nessas crianças [trans] e me dei conta de que se eu fosse uma criança hoje, eu provavelmente iria querer usar testosterona. [...] Porém, para a maioria das butches da minha geração, 'esse barco já zarpou', como minha amiga Gayle Rubin, a grande intelectual sapatão, disse. Depois dos sessenta e cinco [anos de idade] a maioria das pessoas não quer passar por grandes cirurgias por razões que não sejam uma questão de vida ou morte (NEWTON, 2018, p. 09-11). ${ }^{4}$

Assim sendo, nos quatro primeiros capítulos de My Butch Career - em ordem: "A Hard Left Fist", "A Writer's Inheritance", "Manhattan Tomboy" e "California Trauma" - acompanhamos o coming of age de Newton como uma garota "mais masculina" na Manhattan dos anos 1940 e 1950. Neles a autora produz uma meticulosa contextualização de suas raízes familiares, apresenta a infância financeira e afetivamente instável em Nova lorque e a adolescência afluente, porém traumática, na Califórnia, além da aguda percepção de si como masculina e diferente das outras garotas. Ademais, são abordadas interessantes questões de gênero, sexualidade, classe e psicanalíticas da época e, em especial, o modo como o ocultamento do desejo e interesse erótico-afetivo por mulheres era percebido e vivenciado por Newton em um período macarthista de intensa perseguição e patologização da homossexualidade.

No que diz respeito aos seus pais, a autora lança cores carismáticas a ambos, construídos longamente como figuras fortes, multifacetadas, de esquerda e de personalidades marcantes e progressistas. O pai era judeu, ex-membro do Partido Comunista, veterano da Guerra Civil Espanhola, além de eminente psicanalista de Nova lorque (na verdade, ela se prolonga na relação com o principal entre seus "três pais judeus"; homens com os quais sua mãe possuiu relações afetivas significativas). Já a mãe de Newton era uma "WASP" 5 e filha deserdada de um general do exército

\footnotetext{
3 "Drag queens" e "female impersonators" poderiam ser traduzidas ao português brasileiro como "transformistas", embora ałualmente a categoria "drag queen" já esteja bastante espalhada na América do Sul. É preciso ter em mente que tais categorias, suas práticas, concepções e significados são altamente dinâmicos e o universo analisado por Newton nos anos 1960 certamente difere das drag queens atuais, e mais ainda em termos de diferenças nacionais e culturais. Sobre o universo das drag queens no contexto brasileiro, consultar a pioneira e excelente etnografia de Anna Paula Vencato (2002). ${ }^{4}$ No original: "Why not transition? Generational and autobiographical factor are the most important reasons. As a child I did not think of myself as a girl trapped in a boy's body. [...] Recently I saw the excellent PBS Frontline film Growing Up Trans. [...] I had to face the fact that I was seeing myself in these children and realized that if I were a child now, I likely would have wanted that testosterone. [...] But for the majority of butches of my generation, 'that ship had sailed,' as my friend Gayle Rubin, the great butch intellectual, said. After sixty-five, most people don't want major surgery for any reason except in matters of life and death." (NEWTON, 2018, p. 09-11).

5 "WASP" é um acrônimo para "White Anglo-Saxon Protestant" ou "Anglo-Saxão Branco e Protestante". Tal sigla, em geral, é associada a grupos influentes e poderosos, de classes médias-altas e elites econômicas na América do Norte.
} 
estadunidense, embora compartilhasse com a avó e a bisavó da autora o envolvimento em lutas abolicionistas, por igualdade racial, assim como em lutas feministas e sufragistas iniciadas ainda no Século XIX.

Por sua vez, "Baby Butch", o quinto capítulo do livro, situa o final da adolescência da autora, os desafios e crises de ser uma jovem lésbica e masculina em uma época em que lobotomias, aprisionamentos, choques elétricos e internações psiquiátricas compulsórias de homossexuais eram comuns nos Estados Unidos. Também apresenta a sua aproximação do universo lésbico nova-iorquino pré-Stonewall, ${ }^{6}$ os bares de Greenwich Village, assim como um interessante complexo categorial das identidades lésbicas da época, em especial, nuances e variações do binarismo "butch" e "femme".

Sobretudo no sexto capítulo - "Anthropology of the Closet" - a autora finalmente discorre sobre o seu contexto de formação na antropologia cultural norte-americana e os riscos do seu primeiro trabalho de campo em meio a uma conjuntura institucional predominantemente masculina, heterossexual e branca. Além disso, aborda as resistências ao seu tema e lócus de pesquisa considerando a concepção dominante, à época, de que o trabalho de campo na antropologia deveria ocorrer somente em um "lá" bem distante dos Estados Unidos.

É também nesse capítulo que Newton aborda mais diretamente, embora de modo sucinto, os detalhes sobre a sua desafiadora experiência entre as drag queens das cidades de Chicago e Kansas City. Em um olhar retrospectivo para sua primeira obra, aproxima a sua própria identidade como lésbica butch - sendo impelida na época a se adequar a um ideal feminino obrigatório com as próprias identidades e performances dos sujeitos por ela investigados em Mother Camp. A seu ver, a sua experiência de campo a fez constatar que tanto ela quanto seus interlocutores compartilhavam - cada qual a sua maneira - de um processo de construção "artificial" do "feminino" através de práticas cotidianas. Nas palavras de Newton:

Eu também pratiquei um transformismo feminino de um tipo diferente, mais intensamente ao longo dos meus anos de ensino médio e de faculdade. Desde que escrevi Mother Camp, eu sempre adorei o fazer drag, o qual eu compreendi como uma performance teatral relacionada a minha vida íntima e a minha própria experiência. (NEWTON, 2018, p. 118). ${ }^{7}$

Já em seu sétimo capítulo - "Lesbian Feminist New York" - acompanhamos o intenso envolvimento de Newton com os movimentos feministas de segunda onda em Nova lorque, logo após o término do doutorado. No sexto e sétimo capítulos afloram o caráter intelectual e politicamente arrojado de Newton para a época, assim como o fato de que seu reconhecimento como pioneira e precursora não the foi concedido cedo e acabou the custando muito caro. Em uma conjuntura acadêmica conservadora na primeira metade dos anos 1970, Newton relata ter o seu primeiro pedido de "tenure" surpreendentemente negado como professora universitária, mesmo tendo um livro já publicado e receber boas avaliações acadêmicas.

Esse fato teve um efeito devastador, pois à época isso resultava em demissão. Mesmo tendo um doutorado em uma universidade de elite - cuja banca de defesa contava, além de Schneider, com Clifford Geertz e Julian Pitt-Rivers -, e mesmo tendo como prognóstico uma carreira brilhante, Newton se viu com uma inesperada mácula no currículo. A esse episódio a autora não tem dúvidas em atribuir ao machismo, à homofobia e à lesbofobia institucionais da época. Tal baque quase a fez abandonar a antropologia e a carreira acadêmica de conjunto.

Nos capítulos seguintes - "The Island of Women"; "In-Between Dyke"; "Paris France" e Butch Revisited" - acompanhamos novas e tórridas paixões da autora entre o México e a França, além de suas considerações sobre as cisões, as polêmicas e as pensadoras do feminismo francês, como Monique Wittig, Hélène Cixous e Antoinette Fouque, na segunda metade dos anos 1970, quando viveu em Paris.

O livro se encerra de um modo um tanto abrupto, no início dos anos 1980, abarcando, portanto somente a primeira metade da vida da autora, a qual se aproxima, hoje em dia, dos 80 anos de idade. Essa limitação temporal talvez se deva aos problemas de saúde enfrentados por Newton, os quais atrasaram o desenvolvimento do manuscrito e, suponho, o reduziram. De modo irônico, aliás, a obra se finda justamente com o início do reconhecimento do seu pioneirismo e de suas contribuições, já em um clima acadêmico distinto nos Estados Unidos. O livro também aborda, embora com frustrante brevidade, o envolvimento e participação da autora na conferência sobre

\footnotetext{
${ }^{6}$ A Revolta de Stonewall foi uma sequência de dias de conflitos em resposta à perseguição e violência policiais aos bares gays (e seus frequentadores) da cidade de Nova lorque, ocorrida no mês de junho de 1969. A data, portanto, completou 50 anos em 2019. No entanto, embora Stonewall tenha se convertido em um inequívoco e poderoso símbolo de lutas transnacionais pelos movimentos gays liberacionistas, e mais tarde para os movimentos LGBTQ, existiram outros movimentos e organizações similares anteriores nos Estados Unidos - como os movimentos homófilos dos anos 1950 e início dos anos 1960 - os quais não deveriam ser obliterados.

${ }^{7}$ Tradução livre de: "I, too, had practiced female impersonation of a different kind, most intensely during my high school and college years. Since writing Mother Camp, I had always loved drag, which I recognized as a theatrical perfomance related to my inner life and experience." (NEWTON, 2018, p. 118).
} 
sexualidade feminina no Barnard College de Nova lorque em 1982, a qual resultaria pouco depois na renomada coletânea Pleasure and Danger: Exploring Female Sexuality editada por Carole Vance (1984).

Essa recorte temporal, portanto, resulta em deixar de fora as considerações de Newton sobre inúmeras outras questões relevantes em sua vida, como por exemplo, o seu profundo envolvimento posterior com o esporte Agility - o qual envolve o treinamento e exibição de cachorros de raça assim como o contexto de produção e escrita de suas demais obras, como Cherry Grove, Fire Island: Sixty Years in America's first Gay and Lesbian Town (1993) e o livro de ensaios Margaret Mead Made Me Gay: personal essays, public ideas (2000). ${ }^{8}$

De todo modo - e levando esses elementos em consideração - My Butch Career: a memoir é um importante documento para consulta a interessadas/os em estudos queer, estudos de gênero e sexualidade, estudos feministas, estudos lésbicos, assim como em teoria e história da antropologia cultural norte-americana. Além disso, vários de seus capítulos são úteis tanto para utilização em cursos de graduação quanto de pós-graduação nas temáticas supracitadas. Para além desses campos, no entanto, o livro possui qualidades narrativas que o fazem ser facilmente apreciado por um público não-acadêmico mais amplo. Se trata, afinal, de uma prodigiosa viagem pelas memórias de "dor e glória" de Esther Newton e sua incidência no universo político-intelectual dinâmico e turbulento da segunda metade do Século XX. Essa espécie de autoarqueologia reflexiva da autora - assim como de ativistas e intelectuais da sua geração - contribui valorosamente, por fim, para a consolidação, o reconhecimento e a "sedimentação" qualificada de importantes camadas dos "conhecimentos queer" no período em questão.

\section{Referências}

BUTLER, Judith. Problemas de Gênero: feminismo e subversão da identidade. Trad. de Renato Aguiar. Rio de Janeiro: Civilização Brasileira, 2003 [1990].

NEWTON, Esther. Mother Camp: Female Impersonators in America. Chicago, IL: University of Chicago Press, 1979 [1972].

NEWTON, Esther. Cherry Grove, Fire Island: Sixty Years in America's First Gay and Lesbian Town. Durham, NC: Duke University Press, 1993.

NEWTON, Esther. Margaret Mead Made Me Gay: Personal Essays, Public Ideas. Durham, NC: Duke University Press, 2000.

NEWTON, Esther; WALTON, Shirley. Womenfriends: A Soap Opera. New York: Friends Press, 1976.

RUBIN, Gayle. "The Traffic in Women: Notes on the 'political economy' of Sex”. In: REITER, Rayna (Ed.). Toward an Anthropology of Women. New York: Monthly Review Press 1975, p. 157-210.

RUBIN, Gayle. "Thinking Sex: notes for a radical theory of the politics of sexuality". In: VANCE, Carole (Ed.). Pleasure and Danger. New York: Routledge and Kegan Paul, 1984, p. 267-319.

RUBIN, Gayle. "Esther Newton Made Me a Gay Anthropologist". American Anthropologist. v. 120, n. 4, p. 852-853, dez. 2018a.

RUBIN, Gayle. "Estudando Subculturas Sexuais: Escavando as etnografias das comunidades gays em contextos urbanos da América do Norte". Trad. de Carlos Eduardo Henning e Glauco B. Ferreira. Teoria e Cultura. Programa de Pós-Graduação em Ciências Sociais, UFJF, v. 13, n. 1, p. 247-288, $2018 b$. Disponível em: https://periodicos.ufj.br/index.php/TeoriaeCultura/article/view/12413. Acesso em: 15/03/2019.

RUBIN, Gayle. "Geologias dos estudos queer: um déjà vu mais uma vez". Trad. de Paula Nogueira Pires Batista, Roberto M. Xavier Reis, Carlos Eduardo Henning e Glauco B. Ferreira. Sociedade e Cultura, Goiânia, v. 19, n. 2, p. 117-125, jul./dez 2016. Disponível em: https://www.revistas.ufg.br/ fchf/article/view/48676/23898. Acesso em: 15/03/2019.

VANCE, Carole (Ed.). Pleasure and Danger: exploring female sexuality. Boston: Routledge \& Kegan Paul, 1984.

\footnotetext{
${ }^{8}$ O livro de artigos e ensaios Margaret Mead Made Me Gay (2000), aliás, tem como título justamente uma homenagem lúdica a outra antropóloga - no caso, obviamente, Margaret Mead (1901-1978) - pelo seu papel "salvador" para Newton. Newton recorda que nos momentos em que se sentia em crise com a sua dissidência em termos de gênero e sexualidade na adolescência, ela invocava para si mesma as leituras de Mead e repetia, quase como um mantra, ao se trancar em seu quarto: "Tudo é relativo! Tudo é relativo...". Figura tarimbada no rádio e na TV entre os anos 1950 e 1970, Margaret Mead contribuiu decisivamente para a popularização de massas das noções básicas associadas ao relativismo cultural nos Estados Unidos.
} 
VENCATO, Anna Paula. Fervendo com as Drags: corporalidades e performances de drag queens em territórios gays da ilha de Santa Catarina. Dissertação de Mestrado em Antropologia Social, Programa de Pós-Graduação em Antropologia Social, UFSC, Florianópolis, 2002. Disponível em: http://repositorio.ufsc.br/xmlui/handle/123456789/84381. Acesso em: 15/03/2019.

Carlos Eduardo Henning (carloseduardohenning@gmail.com) é Professor Permanente do Programa de Pós-Graduação em Antropologia Social e da Faculdade de Ciências Sociais da Universidade Federal de Goiás. Pesquisador do Ser-Tão - Núcleo de Ensino, Extensão e Pesquisa em Gênero e Sexualidade. Atualmente realiza período de pós-doutorado no Departamento de Antropologia da USP e no Institute of Latin American Studies da Columbia University na cidade de Nova lorque. Tem experiência em pesquisas em antropologia urbana, antropologia das relações de gênero e sexualidade, e antropologia do curso da vida e da velhice.

\section{COMO CITAR ESSE ARTIGO DE ACORDO COM AS NORMAS DA REVISTA}

HENNING, Carlos Eduardo. "A dor, a glória e o charme butch de Esther Newton". Revista Estudos Feministas, Florianópolis, v. 27, n. 2, e65259, 2019.

\section{CONTRIBUIÇÃO DE AUTORIA}

Não se aplica.

\section{FINANCIAMENTO}

Não se aplica.

CONSENTIMENTO DE USO DE IMAGEM

Não se aplica.

\section{APROVAÇÃO DE COMITÊ DE ÉTICA EM PESQUISA}

Não se aplica.

\section{CONFLITO DE INTERESSES}

Não se aplica.

\section{LICENÇA DE USO}

Este artigo está licenciado sob a Licença Creative Commons CC-BY International. Com essa licença você pode compartilhar, adaptar, criar para qualquer fim, desde que atribua a autoria da obra.

\section{HISTÓRICO}

Recebido em 19/05/2019

Aprovado em 12/06/2019

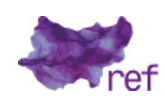

